\title{
A SUBJETIVIDADE COMO OBJETO DA(S) PSICOLOGIA(S) ${ }^{1}$
}

\author{
Kleber Prado Filho \\ Simone Martins \\ Universidade Federal de Santa Catarina, Florianópolis, Brasil
}

RESUMO: Este texto busca traçar uma história da colocação da subjetividade como objeto para as várias psicologias ao longo do século XX. Este conceito nasce no campo da filosofia do conhecimento migrando no final do século XIX para a psicanálise, de onde passa para os domínios da psicologia ganhando um tratamento histórico, social e político no final do século XX, apontando, a partir de então, para uma problematização dos processos de singularização como foco de estudo das psicologias contemporâneas.

PALAVRAS-CHAVE: subjetividade; singularidade; psicologia; Michel Foucault.

\section{SUBJECTIVITY AS THE OBJECT OF PSYCHOLOGY(IES)}

ABSTRACT: This text intends to trace a history of where subjectivity is placed as the object for many different psychologies throughout the twentieth century. This concept originates from the field of philosophy of knowledge, migrating to psychoanalysis near the end of the nineteenth century, from where it moves to the domains of psychology, gaining a historical, social and political treatment at the end of the twentieth century, from then on, pointing to an inquiry on the process of singularization as the focus of study for contemporary psychologies.

KEYWORDS: Subjectivity; singularity; psychology; Michel Foucault.

Dizer, simplesmente, que o "homem" é objeto da ciência psicológica ou das várias psicologias não é suficiente, porque esta entidade genérica, em princípio, é objeto comum a todas as ditas "ciências humanas" dedicadas ao seu estudo. Resta entender como esta disciplina desenha a partir desta abstração genérica seus sujeitos concretos, entender como são construídos os objetos neste campo, além de caracterizar o que singulariza o olhar das psicologias entre as ciências humanas: este moderno olhar sobre o "psicológico".

Numa primeira aproximação, talvez se possa tributar a especificidade das psicologias a uma suposta "descoberta" do sujeito psicológico; melhor, ao nascimento deste sujeito nos domínios do discurso ocidental moderno, científico, ou à sua emergência como figura correlata deste discurso, considerando que esta era uma figura inexistente na cultura ocidental antes do surgimento da psicologia científica na passagem do século XIX ao XX.

Mas, tratar do nascimento de um sujeito nos domínios da psicologia implica falar da sua colocação como objeto para um discurso científico socialmente autorizado a enunciar verdades a respeito de instâncias psicológicas que compõem este sujeito: o psiquismo, a cognição, a "mente", a consciência, a identidade, o self; mas também, as percepções, as interpretações, e uma certa dimensão "intrapsíquica", das emoções, do desejo, do inconsciente - o "reino da subjetividade". Implica, portanto, enunciar o "psicológico" objetivando tais instâncias: construindo-as como "realidades psíquicas", universalizando-as, substan- cializando-as e naturalizando-as, ancorando-as nas objetividades do corpo e da natureza, bem ao estilo do modelo de ciência da época.

Suspeitando de tais naturalizações deve-se, contemporaneamente, colocar em questão a sua produção histórica em jogos de verdade, tomando-as como figuras de um discurso/prática especializado não apenas no conhecimento como também em intervenções sobre o "psicológico". Em seu livro "A invenção do psicológico", Figueiredo (1994) trata da produção histórica desta dimensão de existência subjetiva ligada aos jogos do conhecimento moderno, que designa um campo de experiências do sujeito, apontando que antes do nascimento das psicologias a experiência psicológica não existia, bem como não existiam a própria materialidade da "substância psíquica", a existência psicológica e a percepção de si mesmo como ente subjetivo, que dão forma ao campo de experiências do sujeito moderno, compondo sensações de privacidade e intimidade que ele vivencia como "reais" e "naturais".

Ainda, conforme o mesmo autor, alguns acontecimentos sociais constituem condições históricas para o nascimento deste sujeito psicológico remetido a uma instância de subjetividade ${ }^{2}$, correlativamente ao surgimento de um discurso psicológico na modernidade: a emergência do humanismo renascentista nas artes e na filosofia dos séculos XIV e XV; a reforma pastoral da Igreja Católica no século XVI; e o centramento da cultura moderna na figura do "homem" a partir do século XVII com o Iluminismo, resultando numa recorrente problematização mo- 
derna do sujeito na filosofia, nas ciências, mas também na vida cotidiana.

Estes acontecimentos são fundamentais para o nascimento de um conhecimento psicológico de cunho científico justamente porque demonstram uma primazia de atenção ao sujeito. A reforma protestante, por exemplo, não deve ser tomada como problema meramente religioso, mas centralmente social, implicando uma recusa dos modos de condução pastoral da Igreja Católica e dos modos de subjetivação e individuação ligados à ética católica, caracterizando aquilo que Foucault (2002) denomina "revolta das condutas", ou, um exercício de liberdade do sujeito no terreno religioso. Por outro lado, a figura nietzschiana da "morte de Deus" deve ser encarada não como o fim do dogma cristão, mas como o fim da hegemonia do pensamento mágico religioso e surgimento de um pensamento humano, de uma filosofia e uma ciência centradas no homem, no sujeito cognoscente. Nesta mesma direção, o trabalho de Figueiredo e Santi (2002) - "Psicologia: Uma (nova) introdução" - aponta o surgimento da "subjetividade privatizada" como campo de experiência histórica, individual e cotidiana na passagem à modernidade.

Tomando o nascimento de um conhecimento psicológico de caráter científico no final do século XIX pode-se observar certa "dança de objetos" nos desenvolvimentos deste campo ao longo do século XX, ligada ao surgimento de várias psicologias concorrentes entre si, denotando não uma unidade, nem linearidade, mas sim, diversidade e divergência de abordagem dos "fenômenos psicológicos":

1. O “objeto primordial”, quase mítico, senão místico, é a "mente"; esta abstração idealista, subjetivista, com fortes influências da concepção cristã de alma como sinônimo de existência imaterial e do pensamento dicotômico cartesiano, que bebe da mesma fonte. Ao longo da primeira metade do século XX este termo ainda era admitido como objeto científico, mas passa a ser questionado posteriormente por suas imprecisões e impregnações metafísicas, perdendo confiabilidade na segunda metade do período.

2. Outro objeto a surgir é o fragmento psíquico - com Wundt - unidade do psiquismo, do funcionamento psíquico ou do processo psicológico: as capacidades, a cognição, recusa do animismo cristão, mas confirmação do idealismo. O fragmento psíquico é tributário da concepção mecanicista de que é possível compreender o todo desmontando-o, analisando suas partes e remontando-o, predominante no modelo clássico de ciência vigente à época.

3. Depois surge o comportamento, inaugurado por Watson em 1910 e depois recolocado por Skinner com a introdução da noção de “operante": exterioridade, mecanicismo, objetivismo e sujeição estrita ao método científico. No entanto, apesar de reproduzirem o frag- mentarismo e o mecanicismo da época, o trabalho de Wundt e o behaviorismo apontam para diferentes direções: enquanto o primeiro busca fazer um mapeamento da consciência a partir de uma composição dos processos psíquicos e das capacidades cognitivas, o segundo centra sua atenção na relação "estímulo-resposta" e nos aspectos operantes do comportamento, recusando os conceitos de consciência e de subjetividade.

4. Emergem as percepções, o campo perceptivo que configura o campo psicológico, que por sua vez singulariza o sujeito. Objeto colocado pela gestalt que, apoiada no método fenomenológico, busca superar o fragmentarismo e o mecanicismo vigentes, propondo uma psicologia e um sujeito mais integrados.

5. O próprio corpo surge como objeto para a ciência psicológica com Reich, também na primeira metade do século XX, numa tentativa de superar o mentalismo. Esta perspectiva é retomada e renovada no final do século, atualizando este esforço no sentido de quebrar a força da dicotomia cartesiana corpo $\mathrm{x}$ mente nos domínios do discurso psicológico.

6. Os discursos são um tradicional alvo de atenção de várias psicologias, analisados e interpretados de múltiplas perspectivas, buscando captar significados atribuídos a objetos e experiências, além de sentidos psicológicos subjacentes às falas dos sujeitos.

7. As relações também emergem como objeto para algumas psicologias, num esforço de superar o individualismo, o mentalismo e as naturalizações ancoradas na neurofisiologia e atualizadas pela neurociência dos anos 1990, buscando fundar tanto o conhecimento quanto o sujeito psicológicos em concepções materialistas, sociais e históricas.

Mostra-se aqui toda uma diversidade de jogos operando no discurso psicológico: fragmentarismo e mecanicismo x perspectivas mais amplas e integradas; subjetivismo $\mathrm{x}$ objetivismo; mentalismo x materialismo; individualismo x coletivismo; naturalismo biologicista $\mathrm{x}$ perspectivas sociais e históricas.

Nesta dança de objetos observável ao longo de todo o século XX pode-se notar ainda um movimento de deslocamento do biológico para o cultural, do natural para o histórico, do individual para o coletivo; o olhar torna-se sempre mais social, histórico e político, desenhando objetos sociais, centrando foco nas relações, mas também no material, buscando superar as concepções idealistas, subjetivistas e individualizantes.

Algumas instâncias mais “integradas” ganham visibilidade a partir de 1940: a consciência, o comportamento; mas também a personalidade (como decorrência da emergência das teorias do desenvolvimento), a individualidade, 
a identidade - objeto por excelência da psicologia social dos anos 1980 - bem como a subjetividade e a singularidade, problematizadas de uma perspectiva social, histórica e política a partir desta mesma década de 1980.

Em verdade o conceito de subjetividade passa do campo da psicanálise para os domínios das psicologias na primeira metade do século passado, mas é somente no seu final que ele se despe de um sentido naturalizado e substancializado de interioridade, passando a ser pensado em termos históricos, sociais e políticos - como produção de subjetividade - apresentando-se contemporaneamente como objeto possível para muitas psicologias de cunho crítico, como alternativa a uma problematização da "identidade", exatamente por buscar dar conta das diferenças. Esta perspectiva histórico-política da subjetividade ganha destaque neste momento em decorrência do declínio do conceito de identidade, que se esgota numa exaltação ao "idêntico": este movimento de se repetir, de se fazer idêntico a si mesmo para facilitar a visibilidade social e permitir a localização e captura pelos poderes. Visibilidade de duas vias: do sujeito que se repete e se reconhece idêntico a si mesmo, e que neste movimento se expõe à vista dos outros, tornando-se identificável e capturável pela lei, pela norma, pela moral. Questão política esta, portanto, ligada a práticas de individualização e identificação social de sujeitos, envolvendo jogos de normalização, formas de reconhecimento de si e dos outros, além de modos de subjetivação, que exigem posicionamento crítico e resistência a uma certa "política das identidades" exercida pelo Estado contemporâneo.

Uma análise arqueológica do conceito mostra que uma primeira problematização da subjetividade surge na filosofia moderna com Kant, que se pergunta sobre as condições de possibilidade para a produção de verdades sólidas, objetivas e universais, válidas para todos, se quem produz conhecimento é sempre um sujeito singular, histórico e, portanto, falível. A questão da subjetividade surge, portanto, no contexto filosófico das preocupações epistemológicas quanto à produção do conhecimento, de forma negativa: como aquilo que precisa ser neutralizado e superado para se ter acesso a uma verdade objetiva. Esta conotação negativa persistiu ao longo de todo o século $\mathrm{XX}$, enfatizando a contaminação do conhecimento por ela, mas as epistemologias contemporâneas argumentam que a subjetividade faz parte do jogo e precisa ser contemplada na produção do conhecimento, por não se opor necessariamente ao critério de objetividade. Além da subjetividade, o poder também tem sido tradicionalmente apontado como contaminador da neutralidade científica, porém Foucault, já na década de 1960, critica esta separação quando liga indissociavelmente em suas análises saber, poder e subjetividade.

Nasce, também com Kant, a figura do sujeito cognoscente: aquele que conhece, desvenda e enuncia verdades; "duplo" da filosofia e da ciência modernas: ao mesmo tempo sujeito e objeto do conhecimento, núcleo da epistemologia clássica, que permanece ainda no centro das epistemologias contemporâneas, de forma revisitada. Apesar da tradição crítica que liga Nietzsche e Foucault levantar esta questão ao longo do século XX, ainda não foi superado esse lugar central do sujeito nos jogos de produção do conhecimento, onde toda a verdade ainda remete e retorna a ele. Sujeito cognoscente, transcendental e universal, porque não é nenhum sujeito concreto em especial e sim, uma abstração genérica que se refere a uma posição e não de um indivíduo, um "descobridor genial".

Após mais de um século o termo migra para o campo dos conhecimentos "psi” pelas mãos de Freud passando a designar uma instância de interioridade, constituindo objeto de estudo científico e campo de experiências do sujeito. De certa forma, a psicanálise freudiana naturaliza e essencializa a subjetividade ao considerá-la inerente ao sujeito, reproduzindo a matriz cristã da interioridade e fazendo dela um enunciado. Nasce agora, correlativamente ao discurso psicanalítico, o sujeito - também universal do inconsciente e do desejo, remetido à sexualidade posta como invariante: este é o contexto do debate de Michel Foucault $(1988,1989,1990)$ com a psicanálise na sua "História da sexualidade". Mas não é da perspectiva psicanalítica que está sendo abordada a questão, até porque uma problematização da subjetividade não é monopólio nem privilégio da psicanálise, e sua importância arqueológica aqui apontada refere-se justamente a este ato de importação do conceito da filosofia para os domínios psi - pelas mãos de Freud - e não exatamente ao novo significado a ele atribuído nos domínios da psicanálise.

Conforme afirmado anteriormente, numa perspectiva mais contemporânea, a subjetividade tomada como objeto construído pelo conhecimento e também como campo de experiências do sujeito não implica naturalmente nem necessariamente interioridade, substância ou permanência. Tradicionalmente as concepções psicológicas apontam para um núcleo, um centro da "consciência", da "personalidade", da "identidade", que pressupõe certa regularidade, previsibilidade e permanência - quando não, "essência" e interioridade - o que permite distinguir os indivíduos uns dos outros. Descentrar a análise da subjetividade deste eixo habitual do desenvolvimento da personalidade e da identidade, tomando-a como resultado da dispersão de forças sociais, implica tratá-la como figura histórica que não tem centro, permanência, inerência ou substância, nem qualquer sentido, naturalizante, biológico, genético ou determinista, e pensá-la em movimento, como virtualidade, efeito holográfico que existe concretamente ali onde não há nada de palpável. Vista desta perspectiva tem menos a ver com uma suposta natureza humana do que com o instável jogo de forças dos enunciados e dispositivos. 
Subjetividade parece sugerir imediatamente interioridade, mas não há nada de natural nessa relação: percebese, arqueologicamente, que subjetividade e interioridade nem dizem respeito a instâncias psicológicas inerentes aos seres humanos, nem se referem a campos equivalentes de experiência ou a termos sinônimos. São enunciados de proveniências diversas que são posteriormente superpostos pelos discursos psicológicos, não necessariamente implicando uma relação de reciprocidade, ao contrário, a subjetividade, além de ser da ordem dos efeitos, é também da ordem da exterioridade - figura da "dobra" em Deleuze $(1988)^{3}$ - produzida em relações saber/poder e também dos sujeitos consigo mesmos, quando estes se colocam como objetos para um trabalho sobre si.

Então, tanto subjetividade quanto interioridade são produções históricas. Pode-se afirmar com Michel Foucault que, assim como o cristianismo inventou a interioridade, a modernidade inventou a subjetividade - essa é a relação entre estas duas figuras do discurso: a noção de interioridade é anterior a de subjetividade, indicando que o moderno conceito de subjetividade apóia-se arqueologicamente na idéia cristã de interioridade encontrando-se, por isso mesmo, totalmente contaminado por esta concepção, este enunciado. Se os ocidentais cristãos se percebem como seres subjetivos e interiorizados é porque se encontram presos a estes dois enunciados que nascem nessa cultura em diferentes momentos e contextos mas que são colados posteriormente, universalizando-se como natureza humana. Esse é, de certa forma, o trajeto da formação de uma tecnologia confessional no Ocidente, por ele percorrido da hermenêutica de si à hermenêutica do desejo, que é constitutivo do sujeito moderno: meio racional, meio cristão; meio sujeito da razão, meio sujeito da culpa.

Isso levanta ainda uma outra questão, referente à relação entre sujeito e subjetividade - não estariam "colados" um no outro? Cada um (sujeito) com a sua (subjetividade)? Não seriam instâncias simétricas? A resposta é: não! Assim como subjetividade não é sinônimo de interioridade, também não designa necessariamente um conjunto de capacidades, qualidades, sensibilidades, atitudes, reações inerentes a um sujeito tomado como unidade autocentrada, autônoma e consciente. Traçando uma genealogia do sujeito paralelamente a esta arqueologia da subjetividade percebe-se que é apenas na passagem do século XVII ao XVIII que o sujeito torna-se "indivíduo", e é apenas no final do XIX que este indivíduo ganha uma subjetividade. Não há, portanto, simetria entre sujeito e subjetividade, não existe naturalmente esta unidade e esta fidelidade a si mesmo - esta relação, esta colagem das características subjetivas em um sujeito, esta individualização da subjetividade, é resultado dos jogos de normalização e de marcação da identidade, característicos das sociedades Ocidentais modernas.
Vista desta perspectiva a subjetividade é resultado e efeito das relações de saber/poder e remete a sujeitos diversos que não o sujeito universal da razão, da cognição, ou da consciência, nem sujeito autônomo, livre, ator ou agente. Na arqueologia do saber refere-se à categoria filosófica/epistemológica do sujeito cognoscente e ainda ao sujeito do discurso e da linguagem; na genealogia do poder, remete à figura do "indivíduo", sujeito separado, individualizado, marcado pelo poder, identificado e normalizado, sujeito do/para o capital, sujeito da/para a ordem social burguesa; na genealogia da ética refere-se ao sujeito moral: colocado como objeto para si mesmo, objeto de práticas de si, de modos de subjetivação, de estetização. Não há, portanto, em Michel Foucault, um sujeito universal, transcendental e genérico - mas sempre sujeitos históricos e localizados. Se existe em Kant o sujeito universal do conhecimento, em Foucault existe toda uma multiplicidade de sujeitos: de direito, das disciplinas, da norma, da moral, da sexualidade, sujeito produzido pelo conhecimento, porque sua problematização não aponta para uma categoria genérica, mas para sujeitos concretos, regionalizados e historicamente construídos.

A subjetividade se produz na relação das forças que atravessam o sujeito, no movimento, no ponto de encontro das práticas de objetivação pelo saber/poder com os modos de subjetivação: formas de reconhecimento de si mesmo como sujeito da norma, de um preceito, de uma estética de si. Equivale dizer que não é suficiente a objetivação pelo discurso psiquiátrico e pelo jogo da norma para produzir, por exemplo, um louco, mas é necessário ainda que este vá ao encontro da marcação, que ele se reconheça no diagnóstico como sujeito da loucura e o reproduza em si mesmo, subjetivando-se como louco. A resistência aos modos de objetivação e de subjetivação acaba desempenhando importante papel nestes jogos de identificação e reconhecimento de si.

Essa diversidade dos sujeitos implica uma multiplicidade de formas de existência, modos históricos de ser: formas de subjetividade; e para além dessas decorrências em termos de saber/poder deve-se lembrar que numa sociedade capitalista estéticas de subjetividade, fetichizadas, investidas de valor, transformam-se em mercadorias a serem consumidas pelos "indivíduos". Isso reforça a questão das "etiquetas" a serem coladas - a bricolagem no sentido original, francês, de etiquetas a partir das quais construímos uma subjetividade-mosaico num arranjo desconexo. Elas ganham lógica no nosso corpo e, por vezes, de maneira bastante incoerente, resultando numa imprevisibilidade do sujeito. Esse é um dos principais problemas do controle social moderno: como lidar com pessoas que não são regulares e previsíveis, sem uma lógica a ser capturada pelo poder? O poder vive dessa falsa unidade que o jogo das identidades constrói, o que remete à moderna política das identidades que mantém os indi- 
víduos presos ao poder. A questão política do Estado contemporâneo não é apenas manter a ordem social do todo, mas também governar cada um, visto que não há ordem social na sociedade como um todo se cada um dos indivíduos não se submeter ao poder. As técnicas macropolíticas do Estado são conhecidas: a lei, a moral e os grandes conjuntos reguladores. No entanto, quais são as estratégias políticas do Estado em relação aos indivíduos? Elas compõem a moderna política das identidades através da qual o Estado governa cada um de nós, que é debitária da matriz do poder pastoral, a partir do qual um pastor conduz cada ovelha do rebanho de forma individualizada.

No que diz respeito a nós, sujeitos modernos contemporâneos (se é que ainda somos modernos), estamos submetidos a formas históricas de subjetividade: a individualidade, correlativa do discurso liberal, do estatuto do indivíduo e do próprio capitalismo; a identidade, socialmente marcada e normalizada, remetida à sexualidade; a cidadania, resultante da moderna democracia com sua carta de direitos. Nos reconhecemos como sujeitos da razão, conscientes, livres e autônomos (mesmo sabendo que não o somos) - sujeitos ético-morais - além de estarmos "intimamente" ligados a valores morais cristãos (porque estes nos constituem naquilo que nos é mais íntimo). Pensamos racionalmente, agimos capitalisticamente, e sentimos como cristãos, movidos por uma moral de compaixão somos esta bricolagem: simultaneamente competitivos, egoístas, e condescendentes com aqueles que derrotamos no jogo da ambição capitalista - e o efeito de subjetividade que isto gera em nós é a sensação de desconforto e conflito psicológico, que pode ser tomado na verdade como conflito ético: exposição do sujeito a éticas contraditórias, ambíguas, gerando ambivalência. Isso é ser não genérica mas, concretamente, sujeito ocidental-cristãomoderno - estar inscrito nessa tradição cultural e histórica.

Estamos sujeitos a formas históricas de problematização que se apresentam como polaridades discursivas entre: material x espiritual (dilema cristão); corpo x mente (dilema cartesiano); exterioridade $\mathrm{x}$ interioridade (dilema cristão, mas também freudiano); objetividade x subjetividade (dilema epistemológico e também freudiano); animal x racional (dilema filosófico); biológico x cultural (dilema antropológico); individual x social, coletivo (dilema sociológico); eu x os outros (dilema ético-político). Não são poucas as injunções, tampouco o são as lutas da subjetividade. Mas estes não são dilemas do sujeito, mas sim de uma cultura e de uma sociedade que polariza qualidades que se ancoram nos corpos dos sujeitos.

Não se trata aqui exatamente de "verdades" estáveis sobre um objeto palpável "subjetividade", mas de uma perspectiva a partir da qual pode-se visualizar e construir um objeto de saberes e práticas, mas também um campo de experiências psicológicas. E por que todo este exercício de pensamento? Por mera sofisticação? O que isso tem a ver com as psicologias?
Tem tudo a ver: não apenas porque a problematização da subjetividade em Michel Foucault contempla uma concepção de sujeito e uma concepção crítica de subjetividade, mas pelo próprio exercício de um penser autrement "pensar de outra forma" - que não é mero pedantismo considerando que saber e poder encontram-se imbricados, portanto, duvidar dos enunciados que sustentam nossas regularidades subjetivas e sociais, pensar diferente, é ação política: transgressão do discurso, resistência ao poder e prática concreta de liberdade - as três "linhas de fuga" 4 de Michel Foucault.

Esta citação aponta para uma certa política contemporânea da subjetividade, ou, para a colocação das formas de subjetividade como objetos de luta:

Talvez, o objetivo hoje em dia não seja descobrir o que somos, mas recusar o que somos. Temos que imaginar e construir o que poderíamos ser para nos livrarmos deste 'duplo constrangimento' político, que é a simultânea individualização e totalização própria às estruturas do poder moderno.

A conclusão seria que o problema político, ético, social e filosófico de nossos dias não consiste em tentar liberar o indivíduo do Estado nem das instituições do Estado, porém nos liberarmos tanto do Estado quanto do tipo de individualização que a ele se liga. Temos que promover novas formas de subjetividade através da recusa deste tipo de individualidade que nos foi imposta há vários séculos. (Dreyfus \& Rabinow, 1995, p. 239).

Esta reflexão é, em verdade, um exercício de transgressão do discurso visando a desmontagem de algumas naturalizações do psicológico, bem como a desconstrução de algumas verdades aceitas de forma acrítica nos domínios das psicologias. Torna-se importante destacar nesta finalização que o saber psicológico é bastante político, presta-se a uma aplicação política e implica fortes decorrências políticas, até porque contemporaneamente os poderes encontram-se bastante sutilizados, aplicando uma instrumentalização psicológica. Então - o que não é novidade - um posicionamento teórico no campo das psicologias implica posição política, as práticas psicológicas são imediatamente políticas, e é necessário caminhar no sentido de uma psicologia descentrada do sujeito e para além de uma problematização da subjetividade (pelo menos no sentido mais tradicional do termo), que busque dar conta da singularização, porque, se os modos de subjetivação assujeitam, a singularização apresenta-se como estetização de si visando resistir a esta maquinaria moderna de produção da subjetividade e da identidade individuais, construindo novas formas de vida e de ser. Se ao longo do século XX as psicologias têm se caracterizado como "disciplinas científicas de aplicação da norma", é também necessário que elas superem estas práticas passando a se dedicar à promoção de novas estéticas da existência. 


\section{Notas}

1 Informações complementares: Este texto resulta da transcrição de uma aula de encerramento da disciplina "Fundamentos históricos e epistemológicos da Psicologia" ministrada no Programa de Pós-Graduação em Psicologia da UFSC e toma como referência a palestra proferida pelo autor no Seminário Internacional Michel Foucault: Perspectivas, realizado na UFSC em 2004, publicada com o título: "Uma história crítica da subjetividade no pensamento de M.Foucault", no livro: "Michel Foucault: Perspectivas" (Rio de Janeiro, RJ: Achiamé, 2005).

2 O termo "subjetividade" está sendo aqui empregado de forma genérica, sem conotação demarcada, portanto não necessariamente ligado ao sentido a ele atribuído pelo discurso psicanalítico, não necessariamente designando uma instância de interioridade, e recusando todas as formas de substancialização, naturalização e universalização a ele associadas. A arqueologia do conceito desenvolvida pouco mais a frente no texto mostra seu surgimento no campo da filosofia do conhecimento, sua entrada no campo psi pelas mãos da psicanálise freudiana, e sua passagem aos domínios da psicologia onde ganha difusão e multiplicidade de sentidos ao longo do século XX. Portanto, não designa um fenômeno unívoco nem natural, mas uma construção histórica do discurso moderno - um enunciado de um dispositivo - envolvendo jogos de saber, práticas de individualização e normalização, além de efeitos de subjetividade e modos de subjetivação.

3 No texto intitulado: "As dobras ou o lado de dentro do pensamento (subjetivação)" a figura da "dobra" refere-se a uma inflexão da exterioridade que gera efeitos de interioridade; desta perspectiva a interioridade nada mais seria do que mera dobra do discurso.

4 Contra uma argumentação de que as análises de Foucault apontam para uma "filosofia do desespero" por não deixar saídas ao sujeito, vale lembrar que para cada uma das suas aplicações metodológicas resta uma linha de fuga por ele mesmo apontada: a transgressão ao discurso, a resistência ao poder e as práticas de liberdade.

\section{Referências}

Deleuze, G. (1988). Foucault. São Paulo, SP: Brasiliense.
Dreyfus, H., \& Rabinow, P. (1995). Michel Foucault, uma trajetória filosófica: Para além do estruturalismo e da hermenêutica. Rio de Janeiro, RJ: Forense universitária.

Figueiredo, L. C. M. (1994). A invenção do psicológico: Quatro séculos de subjetivação (1500-1900). Linhas de fuga (2. ed.). São Paulo, SP: Escuta.

Figueiredo, L. C. M., \& Santi, P. L. R. de (2002). Psicologia: Uma (nova) introdução. Uma visão histórica da psicologia como ciência (2. ed.). São Paulo, SP: EDUC.

Foucault, M. (1988). História da sexualidade 1: A vontade de saber (7. ed.). Rio de Janeiro, RJ: Graal.

Foucault, M. (1989). História da sexualidade 2: O uso dos prazeres (5. ed.). Rio de Janeiro, RJ: Graal.

Foucault, M. (1990). História da sexualidade 3: O cuidado de si (4. ed.). Rio de Janeiro, RJ: Graal.

Foucault, M. (2002). La hermenéutica del sujeto: curso en el Collège de France (1981-1982).

Kleber Prado Filho é psicólogo pela Pontifícia Universidade Católica de Minas Gerais (PUC-MG), Doutor em Sociologia pela Universidade de São Paulo (USP) e professor do departamento de Psicologia da Universidade Federal de Santa Catarina (UFSC), e do Programa de Pós-graduação em Psicologia da UFSC.

kprado@brturbo.com.br

Simone Martins é mestranda pelo Programa de Pós-graduação em Psicologia da UFSC. smartins27@yahoo.com.br

\section{A subjetividade como objeto da(s) Psicologia(s)}

Kleber Prado Filho \& Simone Martins

Recebido: 20/03/2007

$1^{\text {a }}$ revisão: $27 / 06 / 2007$

Aceite final: 27/07/2007 